\title{
Evaluating a Statewide Pilot Syringe Access Program for Injection Drug Users through Pharmacies in California
}

\author{
Alex H. Kral and Richard S. Garfein
}

Most states in the USA have already overturned or never had laws prohibiting syringes to be sold to injection drug users (IDUs) without a prescription. The goal of selling syringes to IDUs without a prescription is to curtail the transmission of blood-borne viruses such as human immunodeficiency virus, hepatitis $\mathrm{C}$ virus, and hepatitis B virus by providing sufficient access to sterile syringes to obviate the need for sharing blood-contaminated syringes. In at least two states (New York and Connecticut), the change in legislation was accompanied by successful impact evaluations showing reductions in syringe sharing without increasing harm. ${ }^{1-10}$ California passed legislation (Senate Bill [SB] 1159) in 2004 to create a pilot disease prevention demonstration project (DPDP) between January 1, 2005 and December 31, 2010 that would allow pharmacists to sell syringes without prescriptions. The bill mandated that a comprehensive evaluation be completed and submitted to the Legislature and Governor before the law's sunset. The legislation was unique in that it permitted local health jurisdictions (hereafter referred to as "jurisdictions")—cities or counties-to determine whether syringe sales without prescription would be allowed in their jurisdiction. Elected officials would have to affirmatively authorize their health departments to participate. Furthermore, it required pharmacies in participating jurisdictions to enroll with the jurisdictions before selling syringes. While this process was intended to give autonomy to jurisdictions in this large, diverse state, the possibility that not all jurisdictions would approve a DPDP added a significant variable to the evaluation, which differed from other states. This issue of the Journal of Urban Health contains five papers dedicated to the scientific evaluation of California's SB1159.

The state-funded evaluation employed mixed methods/approaches to assessing the effects of the law from the perspectives of IDUs, pharmacists, and key stakeholders. For SB1159 to successfully meet its goal of increasing syringe access, the evaluation focused on four conditions: (1) Did jurisdictions approve the DPDP? (2) In jurisdictions that approved a DPDP, did pharmacies participate? (3) Did participating pharmacies actually sell syringes to IDUs without prescriptions? (4) Were IDUs willing and able to purchase syringes at pharmacies?

The necessity that these four conditions be met for the program to achieve its goal provided a natural experiment exemplifying the complexity of health policy

\footnotetext{
Kral is with the Urban Health Program, RTI International, San Francisco, CA, USA; and with the Department of Family and Community Medicine, University of California, San Francisco, CA, USA; Garfein is with the Division of Global Public Health, Department of Medicine, University of California, San Diego, CA, USA.

Correspondence: Alex H. Kral, PhD, Urban Health Program, RTI International, 114 Sansome Street, Suite 500, San Francisco, CA 94104, USA; and with the Department of Family and Community Medicine, University of California, San Francisco, CA, USA. (E-mail: akral@rti.org)
} 
implementation. Before the law could impact the target population, the first step required jurisdictions to opt into the DPDP. Garfein et al. evaluated the approval of DPDPs by health jurisdictions over time since SB1159 was passed. ${ }^{11}$ They found that, by the end of the second year, only $17(28 \%)$ of the 61 jurisdictions had approved DPDPs, of which three had no registered pharmacies. Most jurisdictions that approved DPDPs did so in the first year, and by 2007 health officials in most jurisdictions without DPDPs reported that they were not planning to seek approval. To better delineate the decision-making process, Rose et al. used qualitative methods to interview senior appointed health officials and elected officials in jurisdictions that approved and did not approve the DPDP. ${ }^{12}$ Their study showed that, in jurisdictions lacking acceptable syringe disposal policies or where SB1159 was considered a low public health priority, health officials sometimes lacked momentum to pursue authorization from their elected officials. In the same study, Backes and Rose $^{13}$ found that elected officials often opposed the program due to expressed concerns about unsafe discard of used syringes, loss of syringe possession as an important law enforcement tool, or a belief that drug users are unable to change behavior.

The second requisite condition towards the implementation of the syringe sales program involved the participation of pharmacies in jurisdictions that approved of the program. Garfein et al. found that, in jurisdictions with approved DPDPs by 2007 , only $18 \%$ of the pharmacies had registered to sell non-prescription syringes. ${ }^{11}$ To better understand the pharmacists' perspectives and practices, Cooper et al. studied two large counties with approved DPDPs. ${ }^{14}$ They found a great variation in the percentage of registered pharmacies in Los Angeles $(17 \%)$ compared to San Francisco $(76 \%)$. Cooper et al. also assessed the third necessary condition, which is whether pharmacies in the program actually allowed syringe sales without prescription. They found that many pharmacists, although registered with the DPDP, reported requiring a proof of a medical condition or plainly refused to sell to suspected IDUs.

Lastly, it was important to assess whether IDUs in health jurisdictions with approved DPDPs actually purchased syringes from participating pharmacies. Riley et al. found that over one third of IDUs in San Francisco had actually bought syringes at pharmacies, although these IDUs mostly disposed of their used syringes at syringe exchange program sites rather than at pharmacies. ${ }^{15}$ They also found that syringe use practices were safer among IDUs that used either of these sources, a scenario which echoes the findings in the New York and Connecticut evaluations. ${ }^{3,8}$

Overall, these studies show that all four conditions for optimal syringe access through SB1159 were met with challenges. The minority of jurisdictions approved of the program, the minority of pharmacies within approved jurisdictions joined the program, the minority of pharmacies that joined the program allowed syringe sales without discrimination, and the minority of IDUs in a city with many pharmacies participating in DPDP ended up purchasing syringes at pharmacies. However, IDUs who were able to purchase syringes were less likely to report sharing syringes, thus achieving the intended goal of SB1159. This suggests a need to remove barriers at all levels in order to further increase syringe access. This can be achieved first by new legislation that removes syringe prescription requirements and any necessity for jurisdictions or pharmacies to approve or join any specific program. Upon removal of the legal barriers, pharmacists may need education about the public health importance of providing syringe access. ${ }^{2}$ It will also be important to work with pharmacies to 
consider ways that they can sell syringes in a way that is not disruptive to their other business and to provide syringe disposal options that are acceptable to IDUs.

\section{ACKNOWLEDGMENTS}

Funding source: National Institute on Drug Abuse grant number R21DA024966.

\section{REFERENCES}

1. Fuller CM, Ahern J, Vadnai L, et al. Impact of increased syringe access: preliminary findings on injection drug user syringe source, disposal, and pharmacy sales in Harlem, New York. J Am Pharm Assoc (Wash). 2002; 42 (6 Suppl 2): S77-82.

2. Fuller CM, Galea S, Caceres W, Blaney S, Sisco S, Vlahov D. Multilevel community-based intervention to increase access to sterile syringes among injection drug users through pharmacy sales in New York City. Am J Public Health. 2007; 97(1): 117-24.

3. Pouget ER, Deren S, Fuller CM, et al. Receptive syringe sharing among injection drug users in Harlem and the Bronx during the New York State Expanded Syringe Access Demonstration Program. J Acquir Immune Defic. 2005; 39: 471-7.

4. Cleland CM, Deren S, Fuller CM, et al. Syringe disposal among injection drug users in Harlem and the Bronx during the New York State Expanded Syringe Access Demonstration Program. Health Educ Behav. 2007; 34(2): 390-403.

5. Deren S, Cleland CM, Fuller C, Kang SY, Des Jarlais DC, Vlahov D. The impact of syringe deregulation on sources of syringes for injection drug users: preliminary finding. AIDS Behav. 2006; 10(6): 717-21.

6. Wright-De Agüero L, Weinstein B, Jones TS, Miles J. Impact of the change in Connecticut syringe prescription laws on pharmacy sales and pharmacy managers' practices. J Acquir Immune Defic Syndr Hum Retrovirol. 1998; 18(Suppl 1): S102-10.

7. Valleroy LA, Weinstein B, Jones TS, Groseclose SL, Rolfs RT, Kassler WJ. Impact of increased legal access to needles and syringes on community pharmacies' needle and syringe sales-Connecticut, 1992-1993. J Acquir Immune Defic Syndr Hum Retrovirol. 1995; 10: 73-81.

8. Groseclose SL, Weinstein B, Jones TS, Valleroy LA, Fehrs LJ, Kassler WJ. Impact of increased legal access to needles and syringes on practices of injecting-drug users and police officers-Connecticut, 1992-1993. J Acquir Immune Defic Syndr Hum Retrovirol. 1995; 10: 82-9.

9. Singer M, Baer HA, Scott G, Horowitz S, Weinstein B. Pharmacy access to syringes among injecting drug users: follow-up findings from Hartford, Connecticut. Public Health Rep. 1998; 113(Suppl 1): 81-9.

10. Reich W, Compton WM, Horton JC, et al. Injection drug users report good access to pharmacy sale of syringes. J Am Pharm Assoc (Wash). 2002; 42 (6 Suppl 2): S68-72.

11. Garfein RS, Stopka TJ, Pavlinac PB, et al. Three years after legalization of nonprescription syringe sales in California (SB1159): where are we now? J Urban Health.

12. Rose VJ, Backes G, Martinez A, McFarland W. Non-prescription syringe sales in California: a qualitative examination of practices among 12 local health jurisdictions. $J$ Urban Health.

13. Backes G, Rose VJ. Primary and secondary analysis of local elected officials decisions to support or oppose pharmacy sale of syringes in California. J Urban Health.

14. Cooper E, Dodson C, Stopka TJ, Riley ED, Garfein RS, Bluthenthal RN. Pharmacy participation in non-prescription syringe sales in Los Angeles and San Francisco counties, 2007. J Urban Health.

15. Riley ED, Kral AH, Stopka TJ, Garfein RS, Reuckhaus P, Bluthenthal RN. Access to sterile syringes through San Francisco pharmacies and the association with HIV risk behavior among injection drug users. J Urban Health. 